\title{
Snowy Owl Banding Project
}

by Bernard C. Haysom, President, Sask. Falconry Association, Regina

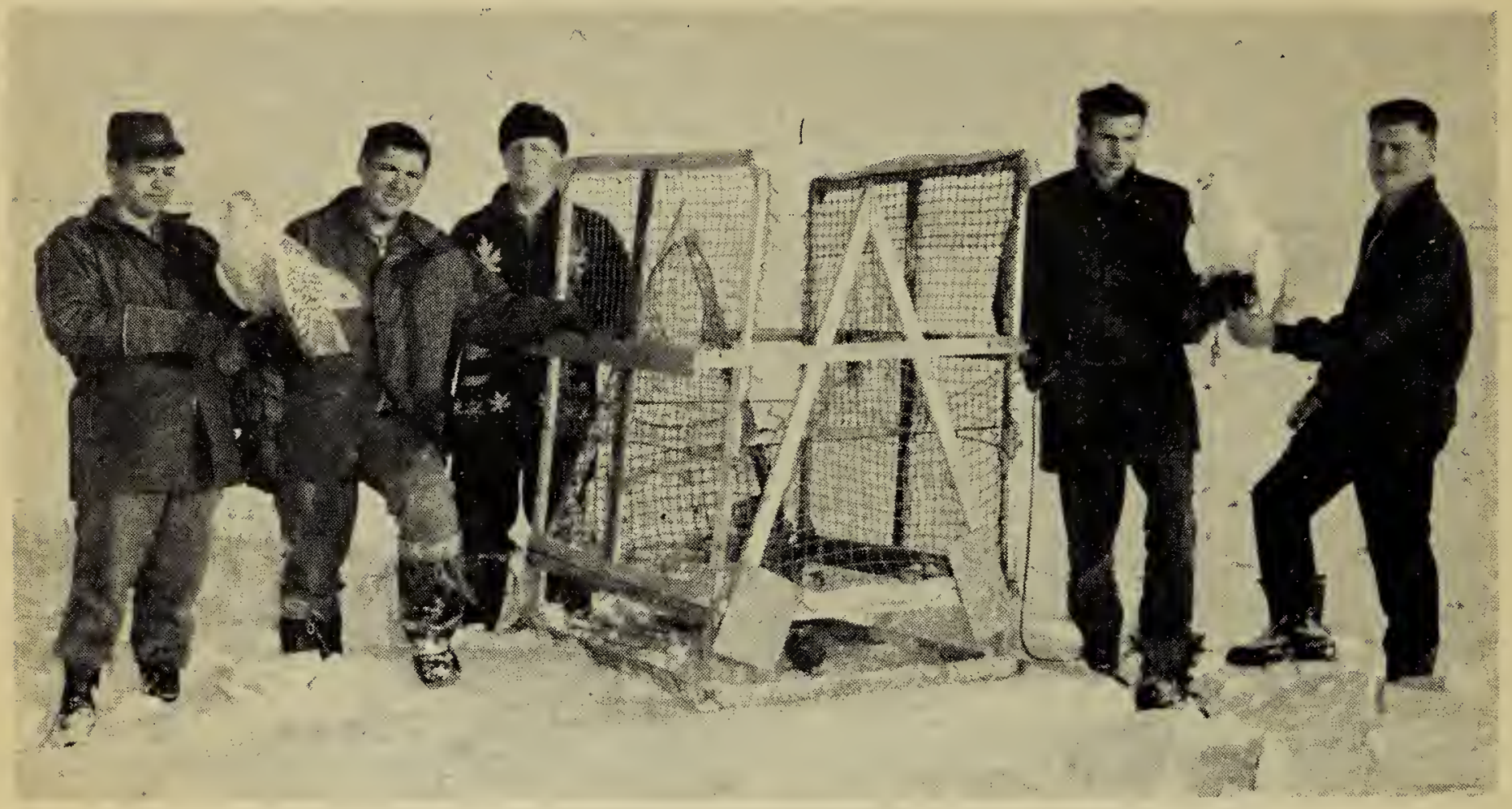

Photo by Fred G. Bard Members of the Saskatchewan Falconry Association with their president (third from left).

In the fall of 1961 the Saskatchewan Falconry Association embarked on a trapping and banding program. As winter was approaching, we decided that the Snowy Owl (Nyctea scandiaca) would be the best species to study. The base of our operations was to be the Association's club house (affectionately known as the "Coop") a few miles west of Regina. Here is where we set up our Norwegian Goshawk trap. Luck smiled on us and in two days of operation we had a male and a female Snowy.

Unfortunately, the weather became blustery and we had to close down our trap since there was a chance we could not get out and check it if the roads were blocked. We reasoned that is was better to lose the chance of banding an owl than to lose an owl in the trap because we could not get to it. However, we did set it again later, and in approximately two weeks of actual operation, we have trapped and banded two males and one female. We also had a return of the female, which was released nine days before at the TV Station, 15 miles awlay from the trap.

The next step in our program is road trapping. We have already been out on one road-trapping expedition
(January 20) and were successful in trapping one female. For this we use Bal Chatris traps built from specifications sent to us by Mrs. Hamerstrom of the Wisconsin Conservation Department. These are smaller, more mobile and easily carried in the car, whereas the "Gos" trap is big and cumbersome (about $3 \times 4 \times 5 \mathrm{ft}$.) and so more suitable for a permanent location.

It is our hope to be able to contribute in some small way to Mrs. Hamerstrom's program. Correspondence with her leads us to believe that we can do just that. Later, we plan to expand and band as many species of birds of prey as possible. We shall be able to band young birds when we are locating nests to get birds for our falconry program. It is our intention to conduct our program of banding as scientifically as possible so that our findings may be used.

We have great hopes for this winter, as all reports say that this will be a banner year for Snowies. We would appreciate receiving any reports of Snowies within a distance of 40 miles of Regina. These reports can be sent to: The Saskatchewan Falconry Association, 750 Cameron Street, Regina. 